\title{
Extracellular vesicles: An emerging platform in gram-positive bacteria
}

\author{
Swagata Bose ${ }^{1, \#}$, Shifu Aggarwal ${ }^{1, \#}$, Durg Vijai Singh ${ }^{1,2, *}$ and Narottam Acharya ${ }^{1, *}$ \\ ${ }_{1}^{1}$ Department of Infectious Disease Biology, Institute of Life Sciences, Bhubaneswar-751023, India. \\ 2 Department of Biotechnology, School of Earth, Biological and Environmental Sciences, Central University of South Bihar, Gaya- \\ 824236, India. \\ \# Contributed equally. \\ * Corresponding Authors: \\ Narottam Acharya, Phone: 91-674-2304278, Fax: 91-674-230 0728; E-mail: narottam_acharya@ils.res.in; narottam74@gmail.com; \\ Durg Vijai Singh, Phone: 91-7978911048; E-mail: durg_singh@yahoo.co.in; singhdv@ils.res.in; dvsingh@cusb.ac.in
}

\begin{abstract}
Extracellular vesicles (EV), also known as membrane vesicles, are produced as an end product of secretion by both pathogenic and nonpathogenic bacteria. Several reports suggest that archaea, gram-negative bacteria, and eukaryotic cells secrete membrane vesicles as a means for cell-free intercellular communication. EVs influence intercellular communication by transferring a myriad of biomolecules including genetic information. Also, EVs have been implicated in many phenomena such as stress response, intercellular competition, lateral gene transfer, and pathogenicity. However, the cellular process of secreting EVs in gram-positive bacteria is less studied. A notion with the thick cell-walled microbes such as gram-positive bacteria is that the EV release is impossible among them. The role of gram-positive EVs in health and diseases is being studied gradually. Being nano-sized, the EVs from grampositive bacteria carry a diversity of cargo compounds that have a role in bacterial competition, survival, invasion, host immune evasion, and infection. In this review, we summarise the current understanding of the EVs produced by gram-positive bacteria. Also, we discuss the functional aspects of these components while comparing them with gram-negative bacteria.
\end{abstract}

doi: 10.15698/mic2020.12.737

Received originally: 30.06 .2020 ;

in revised form: 07.09.2020,

Accepted 23.09.2020,

Published 05.10.2020.

Keywords: virulence, antibiotic resistance, peptidoglycan, $H G T$, biofilm, pathogenesis, quorum sensing, immune response, extracellular DNA, vaccine.
Abbreviations:
BCG - Bacillus Calmette-Guerin, ECM - extracellular matrix, eDNA - extracelllular DNA, $E V$ - extracellular vesicle, $H G T$ - horizontal gene transfer, MGE - mobile genetic element, $M V$ - membrane vesicle, OMV - outer membrane vesicle, $P G N-$ peptidoglycan, PSM - phenol-soluble modulin, $T B$ - tuberculosis.

\section{INTRODUCTION}

Bacterial pathogens quickly respond to changes in the environment to survive and propagate. Pathogenicity of a bacterium is a measure of virulence, which is manifested by the secretion of bacterial virulence factors via membrane blebs for invasion. The secretory vehicles called extracellular vesicles (EVs) are nanoparticles produced by most of the bacteria which have diverse biological functions and broad applications in immunology and biotechnology [1]. The formation of vesicles appears to be a conserved process in both pathogenic and non-pathogenic bacteria. During the past few years, EVs have gained attention in all domains of life. EV release is now considered as a primordial feature of all living cells $[2,3]$. An EV is defined as a spherical, membranous vesicle generated from a microbial cell surface with size ranging from $20 \mathrm{~nm}$ to $500 \mathrm{~nm}$ in diameter. Not only do they differ in size, but they also vary in morphology, composition, and biogenesis. EVs have been coined different names in different organisms such as OMVs (outer membrane vesicles) in gram-negative bacteria and EVs or MVs (extracellular vesicles or membrane vesicles) in gram-positive bacteria. However, to maintain uniformity; the International Society for Extracellular Vesicles (ISEV) recommends EV as a collective term for "particles naturally released from the cell that is delimited by a lipid bilayer and cannot replicate" [4]. EVs contain various macromolecules such as proteins, nucleic acids, phospholipids, adhesins, and lipopolysaccharides required for viru- 
lence, sensing nutrition, and cell-cell communication. Several reports suggest that excess of EVs can be produced due to an abnormality in cell envelope in response to certain stress.

In the 1960s, bacterial EVs were first reported in Escherichia coli, but their existence in gram-positive bacteria gained attention recently [5, 6]. In 1990, Dorward and Garon [6] provided the first evidence of vesiculation in grampositive bacteria (Figure 1). The release of spherical particles occurs by budding in the surrounding environment from the cells. It has been observed in several bacterial species belonging to gram-positive phyla Firmicutes and Actinobacteria [7]. EVs of gram-positive bacteria are of nanometer-size ranging from $10-500 \mathrm{~nm}$ and comprised of a simple architecture containing cell membrane and cytoplasm. Membrane and lumen of the vesicles of the bacteria are derived from the cytoplasmic membrane and the cytoplasm, respectively [8]. Similar to gram-negative bacteria, the EVs in gram-positive bacteria consist of proteins, nucleic acids, and toxins. Besides, gram-positive bacterial EVs do not contain periplasmic components, which is present in gram-negative bacteria $[9,5]$. EVs are involved in cell-tocell communication, sensing nutrients, elimination of competitors, and detoxification of environmental stress. Protein secretion via EVs to extracellular milieu independent of soluble secreted proteins has gained attention as it contributes to pathogenesis. Limited studies on EV release have been shown in few gram-positive bacteria that are relevant to human diseases e.g. Staphylococcus aureus, Listeria monocytogenes, Clostridium perfringens, Streptococcus pneumoniae, Mycobacterium ulcerans, and Bacillus anthracis. Lee et al. (2009) reported for the first time that S. aureus naturally produces EVs [10]. Hong et al. [11] revealed the presence of pathogenic molecules in $S$. aureus EVs that may be involved in the pathogenesis of atopic dermatitis. Also, S. aureus EVs were shown to enhance the development of airway hypersensitivity to inhaled allergens [12]. The isolation of EVs from the culture supernatant of $B$. anthracis is considered as a powerful biological weapon. These findings clearly showed that vesicles in

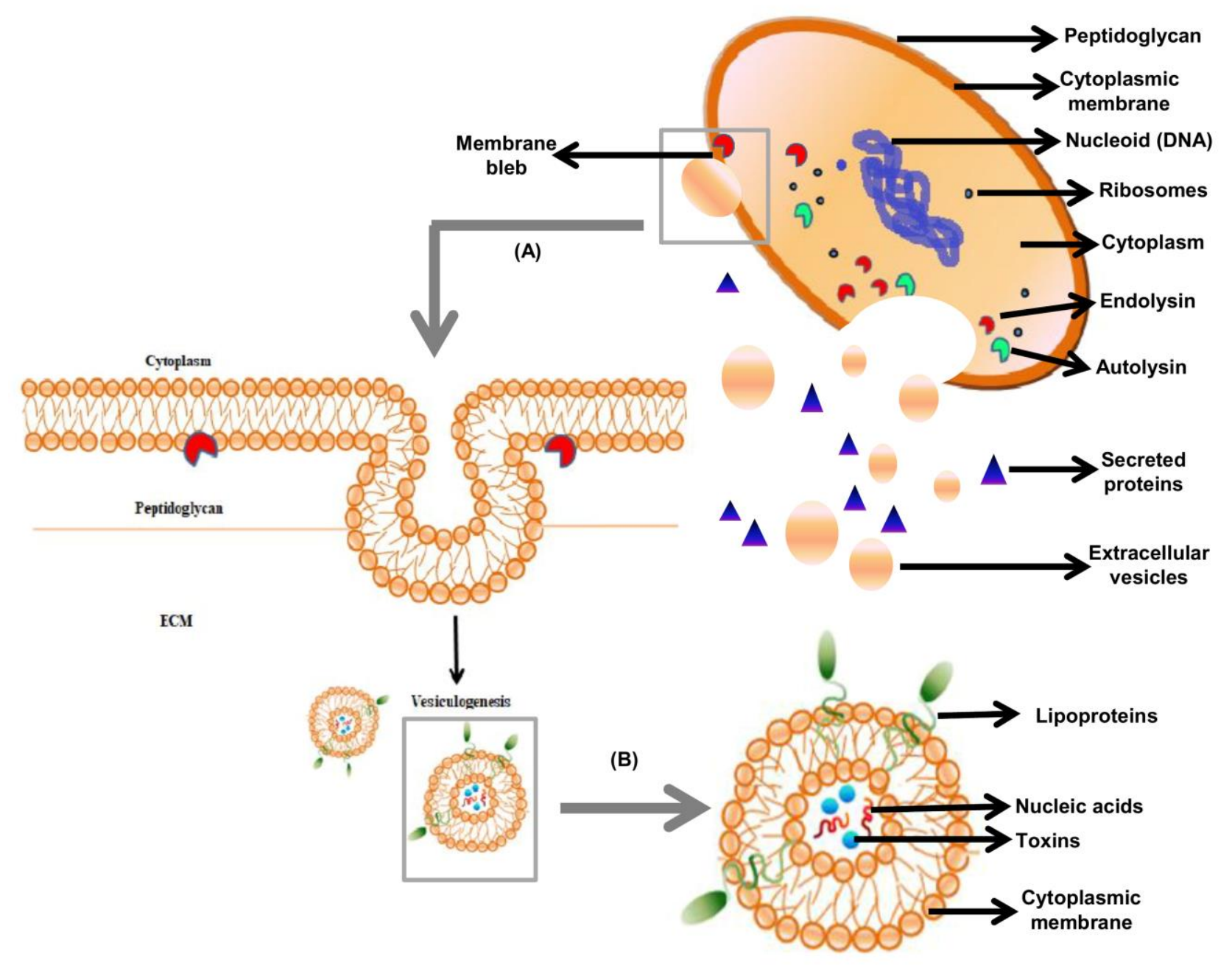

FIGURE 1: Origin and composition of gram-positive EVs. (A) The release of EVs involves diversified events depending on the cell lytic enzyme viz. PGN degradation followed by cytoplasmic membrane bleb protrusion via endolysins and PGN remodelling via hydrolyzing enzyme autolysins. (B) The internal structure of EVs comprising of nucleic acids, virulence factors, and intracellular proteins. 
gram-positive bacteria carried lethal factors and deliver toxins to the host cells [13], thereby showed significance in pathogenesis. In this review, we discuss the roles of EVs in physiology, host-microbial interaction, and their implications in the development of vaccines and antibiotics effective against the pathogenic strains of gram-positive bacteria.

\section{STRUCTURE AND COMPOSITION OF EVS IN DIFFERENT BACTERIA}

Microbial EVs showed certain differences in their morphology and composition. Whereas EVs adhere and fuse rapidly with the outer membrane in gram-negative bacteria, they just attach to the membrane surface in gram-positive bacteria [14]. Shockman and Barrett [15] showed that the architecture of the cell wall in gram-positive bacteria is analogous to that of mycobacteria and fungi, suggesting a similar process of EV biogenesis. EVs released from gramnegative bacteria are spherical and bilayered with size ranging from $10 \mathrm{~nm}$ to $300 \mathrm{~nm}$ in diameter [16, 15]. However, the gram-positive bacteria EVs are of $\sim 20-150 \mathrm{~nm}$ diameters, derived directly from the cytoplasmic membrane [16]. Streptomyces coelicolor EVs are found to be unilamellar with a bilayer membrane ranging from $80-400 \mathrm{~nm}$ in diameter with a width of $150-300 \mathrm{~nm}$ [17]. EVs of 20- $100 \mathrm{~nm}$ diameter in the culture filtrate of $S$. aureus were detected by using a transmission electron microscope (TEM) [10]. Similarly, Bacillus sp. and other gram-positive bacteria were found to shed EVs in the size range of $50-150 \mathrm{~nm}$ diameters $[10,13]$. On the basis of structural and molecular studies, the composition of gramnegative and gram-positive vesicles was analyzed. The gram-negative bacterial EVs contained peptidoglycan, virulence factors, inner membrane, cytoplasmic proteins, DNA, and RNA. On the other hand, the EVs of gram-positive bacteria contained fatty acids, phospholipids, cytoplasmic proteins, membrane-associated virulence proteins, lipoteichoic acid, peptidoglycan, DNA, and sRNAs [16]. The proteomic analysis showed that the vesicles contain proteins and chaperones required for cell wall architecture and carbohydrate metabolism [18]. However, the lipidomic analysis showed that EVs of $B$. anthracis and S. pneumoniae contain fatty acids like myristic acid and palmitic acid [19]. Similarly, analysis of Staphylococcus EVs showed the presence of fatty acids $[20,21]$. The predominant fatty acids found in EVs are palmitic, octadecenoic, stearic, and eicosenoic acids. A summary of the morphology and composition of EVs of gram-negative and grampositive bacteria is given in Table 1.

\section{EVs BIOGENENSIS AND PEPTIDOGLYCAN DEGRADING ENZYMES}

In gram-negative bacteria, EVs are easily pinched-off from the outer membrane, due to the presence of a thin outer cell wall. In contrast, EV biogenesis in gram-positive bacteria is a complex process because of the presence of a thick peptidoglycan barrier. In almost all organisms, the outer layer provides a protective barrier against different stress conditions. Similarly, gram-positive bacteria possess a thick cell wall ranging between $20-40 \mathrm{~nm}$ that helps to withstand the extremities like osmotic pressure, DNA-damaging agents, exposure to antibiotics [22]. Kim et al. [9] reported that peptidoglycan (PGN) is the major component of the cell wall in addition to polysaccharides, proteins, and polymers. The thick PGN layer with a pore size of approximately $2 \mathrm{~nm}$ may prevent the release of EVs with a diameter of $20-400 \mathrm{~nm}$ [23]. Thus, the intriguing question that remains is "how EVs traverse the thick cell wall?" In S. aureus, it was demonstrated that the action of certain PGN degrading enzymes could remodel the cell wall in a way that may facilitate EVs to transit across the cell wall [10]. In Bacillus subtilis, a phage-encoded endolysin, which promotes the pore formation in peptidoglycan layers, facilitates the release of the EVs [24]. In this event, endolysins first weaken the PGN causing $B$. subtilis cells to protrude their cytoplasmic membrane, thus forming membrane blebs, and finally releasing it as EVs. Interestingly, the vesicles from S. pneumoniae were enriched in putative phageassociated endolysin [25]. A predatory role of $S$. aureus EVs has been proposed in which vesicle-associated $\mathrm{N}$-acetylmuramoyl-L-alanine amidase can kill other competing bacteria by PGN degradation and cell lysis, similar to that observed with EVs of Pseudomonas

aeruginosa [14]. In community-associated methicillinresistant Staphylococcus aureus (CA-MRSA) EVs, the cytoplasmic membrane is disrupted through phenol-soluble modulins (PSMs) [10]. In another study, it was shown that S. aureus uses PGN hydrolase activity of two autolysins Atl and Sle1 during cell division resulting in the separation of daughter cells $[26,27]$. However, the role of autolysins in modulating EV release from the cell wall and its regulation is yet to be determined. In mycobacteria, the cell wall is made up of mycolyl-arabinogalactan-peptidoglycan (mAGP) complex. The genesis of EV in mycobacteria is thought to be due to the action of remodeling enzymes or proteins similar to that obtained in EVs biogenesis of $S$. aureus $[28,18]$. All this information ascertains that the disruption of an extensive cross-link of PGN is possible only through the presence of degrading enzymes and surfactant proteins to facilitate EVs to escape from the thick cell wall of gram-positive bacteria (Figure 1).

\section{ROLE OF EVS IN ANTIBIOTIC RESISTANCE}

Bacteria are usually sensitive to antibiotics but carry antibiotic resistance genes present on either chromosome or extra-chromosome that may lead to the development of antibiotic resistance [29]. As part of the adaptive response, pathogenic bacteria show a heavy yield of EVs compared to non-pathogenic bacteria [30,31]. Factors like antibiotics, reactive oxygen species (ROS), lipopolysaccharide, serotype-switching influenced EV production in bacteria [32, 33]. EVs from B. subtilis is enriched in Sun1 protein (also known as YolF), which confers immunity to sublancin antibiotic [34, 35]. Moreover, the large quantity of vesicles from $B$. subtilis was found to be linked with the expression of the lipopeptide antibiotic surfactin. Surfactin destabiliz- 
TABLE 1. Comparison between gram-negative and gram-positive extracellular vesicles.

\begin{tabular}{|c|c|c|c|c|}
\hline SI. No. & Features & Gram-negative EVs & Gram-positive EVs & Ref \\
\hline 1 & Origin & Outer membrane & Cytoplasmic membrane & {$[16]$} \\
\hline 2 & Size & $10 \mathrm{~nm}-300 \mathrm{~nm}$ & $20 \mathrm{~nm}-400 \mathrm{~nm}$ & {$[16]$} \\
\hline 3 & Components & $\begin{array}{l}\text { Outer membrane proteins, periplasmic } \\
\text { proteins, virulence factors, cytoplasmic } \\
\text { proteins, inner membrane proteins, } \\
\text { lipopolysaccharides, phospholipids, and } \\
\text { peptidoglycan }(10 \%-20 \%)\end{array}$ & $\begin{array}{l}\text { Cytoplasmic proteins, membrane- } \\
\text { associated proteins, lipoteichoic acid } \\
\text { (LTA), peptidoglycan }(>50 \%)\end{array}$ & [16] \\
\hline 4 & Genetic components & $\begin{array}{l}\text { sRNA, mRNA, miRNA, luminal and sur- } \\
\text { face associated DNA }\end{array}$ & $\begin{array}{l}\text { sRNA, extracellular and chromosomal } \\
\text { DNA }\end{array}$ & {$[16]$} \\
\hline 5 & Proteins & $\begin{array}{l}\text { Outer membrane: OmpA, OmpC, } \\
\text { OmpF, lipoprotein (Lpp), } \\
\text { periplasmic: Alkaline phosphatase and } \\
\text { AcrA }\end{array}$ & $\begin{array}{l}\text { Single lipid membrane proteins: pen- } \\
\text { icillin-binding, immunoglobulin G- } \\
\text { binding (protein A), staphopain A, } \alpha \text { - } \\
\text { haemolysins, heat-shock protein }\end{array}$ & {$[9,50]$} \\
\hline 6 & Lipids & $\begin{array}{l}\text { Glycerophopholipids, phosphatidyleth- } \\
\text { anolamine, phophotidylglycerol and } \\
\text { cardiolipin }\end{array}$ & $\begin{array}{l}\text { Phosphatidylglycerol, myristic and } \\
\text { palmitic acids }\end{array}$ & {$[9,19]$} \\
\hline 7 & Coagulation & E-selectin, P-selectin, thrombomodulin & $\begin{array}{l}\text { Fibronectin binding protein, staphy- } \\
\text { locoagulase precursor, } \\
\text { Vonwillebrand factor binding protein }\end{array}$ & [9] \\
\hline 8 & Antibiotic resistance & $\begin{array}{l}\beta \text { - lactamase, enzyme } L 5 \text {, multidrug } \\
\text { efflux protein (Mtr, Mex, TolC) }\end{array}$ & $\begin{array}{l}\beta \text {-lactamase, Penicillin- binding pro- } \\
\text { teins: PBP1, PBP2, PBP2a, PBP3 and } \\
\text { PBP4 }\end{array}$ & [9] \\
\hline 9 & $\begin{array}{l}\text { Virulence factor deliv- } \\
\text { ery }\end{array}$ & $\begin{array}{l}\text { Enzymes: phospholipase C, esterase } \\
\text { lipase, alkaline phosphatase, serine } \\
\text { protease Toxins: adenylatecyclase, } \\
\text { cholera, cytolethal distending, PagJ, } \\
\text { PagK1, VacA }\end{array}$ & $\begin{array}{l}\text { InIB, LLO, IgG binding protein Sbl, } \\
\text { protective antigen, lethal factor, } \\
\text { edema toxin, anthrolysin }\end{array}$ & [9] \\
\hline 10 & Bacterial survival & $\begin{array}{l}\text { Hemin- binding protein, TonB- de- } \\
\text { pendent receptors }\end{array}$ & $\beta$-lactamase protein & {$[9,39]$} \\
\hline 11 & $\begin{array}{l}\text { Bacteria adhesion \& } \\
\text { invasion }\end{array}$ & Adhesin/invasin, OmpA & $\begin{array}{l}\text { Plasma binding proteins, staphopain } \\
\text { A }\end{array}$ & [9] \\
\hline 12 & Immune evasion & $\begin{array}{l}\text { Cytotoxic necrotizing factor } 1 \text {, Us- } \\
\text { pA1/A2 }\end{array}$ & $\begin{array}{l}\text { Coagulation factors, antibody degra- } \\
\text { dation and sequestering factors, } \\
\text { complement inhibition factors }\end{array}$ & {$[7,9]$} \\
\hline 13 & Host-cell modulation & $\begin{array}{l}\text { Cytolysin A, VacA toxin, CNF1, heat- } \\
\text { liable enterotoxin, shigatoxin, Cif, fla- } \\
\text { gellin, } \alpha \text {-haemolysin }\end{array}$ & Proteolysin, $\beta 2$ toxin & [9] \\
\hline 14 & $\begin{array}{l}\text { Killing competing bacte- } \\
\text { ria }\end{array}$ & $\begin{array}{l}\text { Endopeptidase L5, murein hydrolase } \\
\text { (Mtl, Slt), peptidoglycan hydrolase }\end{array}$ & $\begin{array}{l}\mathrm{N}-\quad \text { aetylmuramoyl- } \mathrm{L}-\text { alanine } \\
\text { amindase }\end{array}$ & [9] \\
\hline \multirow[t]{4}{*}{15} & Biogenesis & $\begin{array}{l}\text { a. Loss or relocation of covalent linkag- } \\
\text { es between the OM and the underlying } \\
\text { peptidoglycan layer }\end{array}$ & $\begin{array}{l}\text { Action of cell wall-degrading en- } \\
\text { zymes; endolysin, autolysin }\end{array}$ & [7] \\
\hline & & $\begin{array}{l}\text { b. Accumulation of peptidoglycan } \\
\text { fragments in the outer leaflet of the } \\
\text { OM }\end{array}$ & & \\
\hline & & $\begin{array}{l}\text { c. Misfolded proteins in periplasmic } \\
\text { space exerting turgor pressure on OM }\end{array}$ & & \\
\hline & & $\begin{array}{l}\text { d. Enrichment of species-specific mem- } \\
\text { brane curvature-inducing molecules }\end{array}$ & & \\
\hline
\end{tabular}


es vesicles leading to the lower amount of recoverable vesicles in the pellet fraction [34].

DNA-damaging agents, UV exposure, and antibiotics induced lytic gene expression stimulate SOS response to trigger vesicle formation in lysogenic strains of $S$. aureus [36]. Likewise, genotoxic stress could promote bacterial lysis after DNA replication, phage assembly, and DNA packaging to release EVs and new phage proteins [24]. $\beta$-lactam antibiotics also weaken the PGN layer causing the cytoplasmic membrane protuberance to release it as EVs [25, 37,38 ]. Proteomic analysis showed that $S$. aureus ATCC 14458 derived EVs contain BlaZ, a $\beta$-lactamase required to degrade $\beta$-lactams [10]. Liu et al. [7] suggested that resistant EVs confer protection to the susceptible bacteria by degrading ampicillin in the environment. Thus, it is clear that EVs play an important role in the establishment of antibiotic-resistant subpopulations either by the transfer of antimicrobial-resistant factors or by horizontal gene transfer (HGT). Andreoni et al. [36] reported that $\beta$-lactam antibiotics like flucloxacillin and ceftaroline weaken the PGN layer, thus increasing vesicle formation in a prophageindependent manner. Also, purified EVs from $S$. aureus protect bacteria from daptomycin, a membrane-targeting antibiotic. Lee et al. [39] reported that vesiculation could occur via both a phage-dependent and phage-independent manner in lysogenic strains of $S$. aureus, based on the nature of the antibiotics [39]. Actinorhodin, an antibiotic, was identified in EV-containing exudate of S. coelicolor [13]. It was suggested that vesicles can serve as decoys for phages and membrane targeting antibiotics and contribute to the survival of the bacterium [38]. In Mycobacterium, Cheng and Schorey [40] proposed that EVs released from Mtbinfected macrophages in combination with antibiotics can be used to treat drug-resistant tuberculosis (TB) [40]. In fact, EVs synergize with TB antibiotics to promote bacterial clearance and reduce lung pathology. Also, EVs increased the efficacy of the antibiotic moxifloxacin in mice infected with Mycobacterium tuberculosis. These observations thus suggest that EVs can provide an immunotherapeutic approach to treat drug-resistant M. tuberculosis [41].

\section{ROLE OF EVs IN VIRULENCE}

The role of gram-positive EVs in infection and bacterial pathogenesis is now an emerging area of research [42, 43]. Since the virulence factors are the principal constituent of EVs, the focus lies on the role of EVs during infection [37]. It has been reported that in several pathogenic bacteria, the vesicles signify vesicular transport as a mechanism for concerted delivery to host cells and tissues [44]. In Cryptococcus neoformans and $B$. anthracis, vesicle content has been associated with virulence. While Cryptococcal vesicles that contain glucuronoxylomannan (GXM), is a potent immunomodulatory molecule, $B$. anthracis EVs containing several toxin components play a role in cytotoxicity $[45,13]$ Moreover, B. anthracis vesicles can deliver their cargo directly to the macrophages either by phagocytosis or by fusion with the plasma membrane [44]. In B. anthracis, the components of anthrax toxin lethal factor (LF), edema fac- tor (EF), and protective antigen (PA) were found in the EV pellet but not in the supernatant, suggesting encapsulation of toxins during EV packaging $[13,46]$.

Virulence factors promoting invasion and dissemination throughout the tissues have been identified in EVs. Collagenase and hyaluronate lyase are involved in promoting invasion, and extracellular matrix (ECM) but serine proteases, like exfoliative toxins, facilitate the disruption of the physical barriers $[47,48,49]$. Lee et al. [10] have demonstrated the presence of virulence-associated proteins in S. aureus EVs. S. aureus EVs delivered virulence factors to host cells in a way similar to that found in gram-negative bacteria [42]. In S. aureus, EVs carried virulence factors, super-antigens, and immunoglobulin-G binding proteins. Two major factors, namely Staphopain A and $\alpha$-hemolysins, can induce apoptosis of the host cell by forming pores and causing cellular invasion [50-54]. EVs from L. monocytogenes include virulence factors listeriolysin $O$ (LLO) and internalin $B(\operatorname{In|B})$ which are necessary for cellular invasion and escape from host vacuoles $[55,56]$. Moreover, pneumolysin present in the EVs of $S$. pneumoniae which is a pore-forming cytolysin is important for pathogenesis [57, 58]. In Mycobacterium, EVs are mainly composed of cytotoxins and other virulent factors. They infect the host cells by releasing their EV content [59]. In a study, Marsollier et al. [60] demonstrated that Mycobacterium ulcerans EVs containing cytotoxin mycolactone showed potent pathogenicity in the host when compared to its isolated form. Other workers also reported that the salicylate-derived mycobactin siderophores of $M$. tuberculosis are essential for bacterial growth in macrophages [61, 62].

\section{EVs AND HOST INTERACTION}

EVs transport various immunomodulatory molecules depending on the pathogen's environmental conditions. Studies showed that EVs play a critical role in niche colonization, adhesion, the transmission of virulence factors, mitigating host immune response, and cytotoxicity. EVs of B. anthracis contain anthrolysin and other related active toxins that induce cytotoxicity in host cells [13]. In S. aure$u s$, the delivery of virulent factors from intact EVs causes cytotoxicity in host cells in a dose-dependent manner [63]. Since the treatment of host cells with a cholesteroldestroying agent $M \beta C D$ prevents the entry of EVs into the host cytosol, it was suggested that gram-positive bacteria follow a cholesterol-rich membranous micro-domain delivery mechanism while interacting with the host cell. Similarly, the PSMs are one of the major contributors in S. aureus pathogenesis and disease progression. PSM possessed surfactant-like property having a cytotoxic effect on leukocytes, epithelial, and endothelial cells of the host [64]. In another study, PSM $\alpha$ peptide showed its potential role in the formation of EVs from S. aureus [17]. These surfactant proteins deform the host lipid layer and trigger bacterial membrane curvature resulting in the production of excess EVs. Recently Wang et al. [65] found that EV-mediated Staphylococcal lipoproteins not only activate NLRP3 inflammasome but also alter the IL-1 $\beta, \mathrm{IL}-18$, and caspase- 1 
activity of the host. In Mycobacteria, EVs employ various techniques to disrupt host immune response [66]. Mycobacterial EVs directly interact with TLR2-signaling and contribute to infection [67]. Interestingly, the TLR2 association with Mtb ligands creates an ambiguity between the entities, as their interaction promotes bacterial clearance as well as an escape strategy for bacteria from the host immune response [68]. Lipoarabinomannan (LAM) in EVs was reported to inhibit CD4+ T-cells function and CD4+ T-cells are required for Mtb clearance [69].

\section{ROLE OF EVS IN HGT}

In bacteria, in addition to transformation, transduction, and conjugation, the fusion of EVs carrying DNA between the cells is a mechanism for HGT $[70,71]$. HGT plays a primary role in the evolution of many organisms through the movement of genetic materials, the spread of antibiotic resistance in bacteria, virulence factors, and pathogenicity. Various reports suggest that there is intra- and interspecies vesicle-mediated gene transfer from Acinetobacter baumannii, Acinetobacter baylyi, and Pseudomonas aeruginosa to E. coli cells [72]. The potential of EVs for interspecies gene transfer relies on the capacity of recipient species to take-up and maintain horizontally acquired DNA. Short linear chromosomal pieces and repetitive DNA sequences are further processed and packaged into EVs for export outside the cell [73]. MVs mediated sub-cellular lateral gene transfer (LGT) is responsible for encoding various metabolic enzymes in Ruminococcus species. For example, Ruminococcus alba vesicles play a role in the horizontal transfer of cellulolytic genes to degrade crystalline cellulose. In S. aureus, transduction is a vital gene transfer process, where mobile genetic elements (MGE) encodes for a varied range of proteins representing diverse virulence factors for antibiotic resistance and host adaptation. Through HGT, MGEs bring adjustment in the genetic level between different isolates of the same lineage at high frequency. Presumably, S. aureus relies on MGE for its selective advancements [74, 75]. Although several reports focused on MGE-mediated DNA transfer, the correlation between MGE in the context of EV remains elusive. In $\mathrm{Ba}$ cillus species, about 112 transposase genes play an evolutionary role in HGT. Ten prophages are involved in gene transfer mechanisms leading to bacterial pathogenicity [76]. The proteome analysis showed phage proteins packaged into EVs as HGT mediators in B. subtilis [24]. It has been observed that such EVs contribute to phage integration into the host chromosome and eventually results in spreading and invasion [7]. Few reports suggest that the acquisition of sensitivity (ASEN) drives the exchange of genetic material between resistant and sensitive cells through phage-mediated EVs. The phage-resistant cells acquire sensitivity via phage receptors produced by susceptible cells [77]. A novel gene exchange mechanism was found in Mycobacterium species called distributive conjugal transfer (DCT), also considered as the fourth kind of HGT generating transconjugants from parental mosaic genomes [78].

\section{EVs AND HOST IMMUNE RESPONSE}

A plethora of studies has highlighted the strength of EVs in inducing host humoral and cellular immune response. EVs have been shown to induce immune response with varying success in different gram-positive bacteria. Olaya et al. [57] showed that the vaccination of mice with EVs of $S$. pneumoniae elicits antibody production against virulent pneumococcal infections. Similarly, immunization of mice with $S$. aureus EVs showed protection from lethal challenge primarily due to Th1 cell-mediated and humoral immunity against Staphylococcal lung infections [79]. A vital role of cell-mediated protection is in clearing the invading pathogen from the host, and EVs are efficient in developing cellmediated immunity [80]. EVs from $B$. anthracis are immunogenic in BALB/C mice in which immunised mice developed a robust IgM response against toxin components. Therefore, vesicle-immunized mice survive for a longer period than the controls after $B$. anthracis challenge [13].

In gram-positive bacteria, arrays of molecules involved in immune evasion have been demonstrated. For example, S. aureus EVs, which contain coagulase enzymes and factors, mediate clot formation when added into the serum $[10,81]$. Thus, EVs might help in the formation of fibrin networks surrounding pathogens, forming an environment with limited access to the innate immune system. EVs from S. aureus also contain super-antigens, lipase, and protein A, which help bacteria to evade the immune system. EVs and associated proteins from lactobacilli modulate the activity of immune cells by affecting host innate and adaptive immune responses [82]. Since EVs are biologically active, they can cause disease without associating with the live cells. The in vitro and in vivo studies show that EVs from S. aureus upregulates pro-inflammatory mediators that elicit the Th17 response with increased production of IgE causing atopic dermatitis-like inflammation [11]. It also induced both Th1 and Th17 neutrophilic pulmonary inflammation facilitating airway hypersensitivity against inhaled allergens [12]. The pathogen-derived EV associated proteins modulate pro-inflammatory properties. It was observed that mice survived longer after $S$. pneumoniae challenge when PspA, a surface protein, packaged in the EVs of a gramnegative bacteria Salmonella enterica strain that was used for intranasal immunization [83]. In Mycobacterium, Gehring et al. [84] suggested that the EVs from pathogenic strains are enriched in lipoproteins, which are considered as TLR2 agonists. Again using Mycobacterium species and Bacillus Calmette-Guerin (BCG), Prados Rosales et al. [67] reported that the modulation in immune response via the cargo content of EVs is TLR2-dependent. A study examined the effect of immunization between EV and BCG in a mouse model to determine their vaccine potential. EV of $M$. tuberculosis showed higher efficacy against $M$. tuberculosis infection without any adjuvant when compared to BCG in mouse immunization [85].

\section{ROLE OF EVs IN BIOFILM FORMATION}

Over the years, a striking feature of bacteria that has gained importance is their ability to form biofilms. Biofilm 
formation confers persistence under diverse environmental conditions, resistance to antimicrobial agents, and facilitates colonization in the host [70]. Bacterial vesicles contribute to biofilm formation and transfer DNA to other bacteria sharing genes involved in antibiotic resistance [8688]. A plethora of studies on the role of EVs in biofilm formation has been investigated in B. subtilis, M. ulcerans, and Streptococcus mutans [34, 60, 89]. EVs were isolated from the $B$. subtilis biofilm [34]. Similar sized EVs have been isolated from both planktonic and biofilm cultures of gram-positive bacteria [34, 85]. Marsollier et al. [60] showed that $M$. ulcerans adopt a biofilm structure with an ECM containing vesicles that are highly cytotoxic. In $L$. monocytogenes, EVs were isolated from planktonic cultures but not from its biofilm [39]. It has been observed that extracellular DNA (eDNA) is one of the significant parts of the biofilm matrix that is sufficient to allow the adherence in the early stages of biofilm formation [90]. Liao et al. [89] demonstrated that $S$. mutans produce eDNA by multiple avenues, including lysis-independent MVs in the planktonic state. Thus, eDNA in EVs of planktonic cultures may play some role in biofilm production and bacterial colonization. Moreover, the vesicle-associated extracellular DNA contributes to biofilm formation by influencing the structural integrity and stability of the biofilm [89]. One of the strategies employed by bacteria to survive in high density is quorum sensing, which produces quorum sensing molecules called autoinducers that help in bacterial adherence and biofilm formation [91]. In S. aureus, the quorumsensing related agr locus controls the expression of the cell wall surface proteins and virulence factors found on the pathogen and its EVs [10, 92]. The virulence factors have been identified within $S$. aureus EVs, suggesting a link between agr locus and production of EVs [93].

\section{EVs AS A VACCINE PLATFORM}

EVs from pathogenic bacteria have the potential to be harnessed as vaccines. By using a lethal sepsis model, it was shown that the Staphylococcal EVs could be used as a potential vaccine. In this study, EVs from genetically engineered $S$. aureus mutant expressing detoxified cytolysins were found to be immunogenic in mice [18]. Previously, Choi et al. [79] showed the potential role of native $S$. aureus derived EVs in inducing adaptive immunity and T-cell responses with no toxicity in mice. They also suggested that the protection conferred by the EVs in immune response was without any adjuvants, thus indicating a powerful vaccine strategy. In contrast, OMV based vaccines against gram-negative 330 bacteria hamper the vaccine application due to the toxicity of lipopolysaccharide [18, 94]. In mycobacteria, EVs are reported to be immunogenic. Few studies showed that the immune response is directed against lipoproteins and bacterial cellular components present in EVs. These studies emphasized the importance of identification of EV-associated components and their role in generating protective immunity, thereby 334 incorporating artificial EVs as vaccine platforms [95].

EVs are stable in the biological fluids, preserve proteins from degradation, and act as an antigenic compound to fight against infections. They are considered the most superior substitute in vaccine delivery. The attention is growing more towards biological compounds than synthetic ones and is an ideal choice in therapeutics. In this context, further investigation on bio-engineered extracellular vesicles would improve the remaining complexities and skepticism.

\section{CONCLUSION AND PERSPECTIVE}

EVs are meant for biological transmission from one cell to another. The secretory pathway fine-tunes the natural processes and regulates the host immune response via intercellular communication among bacteria, fungi, and mammalian cells. Gram-positive bacteria constitute a wide range of pathogenic species causing clinical manifestations. As reviewed here, the naturally occurring EVs play a critical role in intercellular communication between bacteria as well as between bacteria and host. This review describes how gram-positive EVs play a role in biological events and can be potential targets for vaccine development. Compared to OMVs derived from gram-negative bacteria, the biology of gram positive EVs remains undetermined, especially in terms of biogenesis, composition, and uptake. Phenotypic differences in their outer membrane composition and virulence-associated factors may need further investigation to interpret the exact process of vesiculogenesis and their role in the causation of diseases. EVs proteome analysis can pave the way for the identification of virulence factors, cytotoxic molecules, immune-associated components, and various other aspects associated with biogenesis, release, and application-based research meant for better input in vaccine platform and facilitation to humankind. To elucidate the mechanisms, our group focuses on the composition and genetic studies of EV biogenesis in Vibrio cholera and S. aureus. Besides, how the quorumsensing system and its inhibitors regulate the composition of EVs and exchange of macro-molecules during biofilm formation will be informative. Since EVs are involved in HGT, they might play a crucial role in the dissemination of antibiotic resistance phenotype. Bacteria in biofilms are more resistant to antibiotics, and reports are suggesting that EVs from biofilm carried drug-binding proteins, therefore, showed their involvement in antibiotic resistance. Furthermore, it would be equally interesting to study the relationships of EVs with biofilm formation and biofilm matrix.

\section{ACKNOWLEDGMENTS}

In part, the study was supported by funds from the Department of Biotechnology, New Delhi, to the Institute of Life Sciences, Bhubaneswar. SB and SA are grateful to the Institute of Life Sciences, Bhubaneswar, for providing Senior Research Fellowships. The funder had no role in study design, data collection, analysis, or decision to publish or prepare the manuscript. We thank our laboratory colleagues for their helpful discussions and critical comments. We apologize that not all of the works related to this field could be discussed or cited due to space limitations. 


\section{CONFLICT OF INTEREST}

Authors declare that they have read the contents of the paper and do not have any competing interests.

\section{COPYRIGHT}

(C) 2020 Bose et al. This is an open-access article released under the terms of the Creative Commons Attribution (CC BY) license, which allows the unrestricted use, distribution,

\section{REFERENCES}

1. Nagakubo T, Nomura N, and Toyofuku M (2019). Cracking open bacterial membrane vesicles. Front Microbiol 10: 3026. doi: 10.3389/fmicb.2019.03026

2. Molina-Tijeras JA, Gálvez J, and Rodríguez-Cabezas ME (2019). The immunomodulatory properties of extracellular vesicles derived from probiotics: A novel approach for the management of gastrointestinal diseases. Nutrients 11(5): 1038. doi: 10.3390/nu11051038

3. Wolf T, Baier SR, and Zempleni J (2015). The intestinal transport of bovine milk exosomes is mediated by endocytosis in human colon carcinoma Caco- 2 cells and rat small intestinal IEC-6 cells. J Nutr 145(10): 2201-2206. doi: 10.3945/jn.115.218586

4. Théry C, Witwer KW, Aikawa E, Alcaraz MJ, Anderson JD, Andriantsitohaina R, Antoniou A, Arab T, Archer F, Atkin-Smith GK, Ayre DC, Bach JM, Bachurski D, Baharvand $\mathrm{H}$, Balaj L, Baldacchino S, Bauer NN, Baxter AA, Bebawy M,Beckham C, Zavec AB, Benmoussa A, Berardi AC, Bergese $P$, Bielska E, Blenkiron C, Bobis-Wozowicz S, Boilard E, Boireau W, Bongiovanni A, Borras FE, et al (2018). Minimal information for studies of extracellular vesicles 2018 (MISEV2018): a position statement of the International Society for Extracellular Vesicles and update of the MISEV2014 guidelines. J Extracell Vesicles 7(1): 1535750. doi: $10.1080 / 20013078.2018 .1535750$

5. Knox K, Vesk M, and Work E (1966). Relation between excreted lipopolysaccharide complexes and surface structures of a lysinelimited culture of Escherichia coli. J Bacteriol 92: 1206-1217. doi: 10.1128/jb.92.4.1206-1217.1966

6. Dorward DW and Garon CF (1990). DNA is packaged within membrane-derived vesicles of Gram-negative but not Gram-positive bacteria. Appl Environ Microbiol 56(6): 1960-1962. doi: 10.1128/aem.56.6.1960-1962.1990

7. Liu Y, Defourny KA, Smid EJ, and Abee T (2018). Gram-positive bacterial extracellular vesicles and their impact on health and disease. Front Microbiol 9: 1502. doi: 10.3389/fmicb.2018.01502

8. MacDonald IA and Kuehn MJ (2012). Offense and defense: microbial membrane vesicles play both ways. Res Microbiol 163(9-10): 607618. doi: 10.1016/j.resmic.2012.10.020

9. Kim JH, Lee J, Park J, and Gho YS (2015). Gram-negative and Grampositive bacterial extracellular vesicles. Semin Cell Dev Biol 40: 97104. doi:10.3389/fmicb.2018.01502

10. Lee EY, Choi DY, Kim DK, Kim JW, Park JO, Kim S, Kim SH, Desiderio DM, Kim YK, Kim KP, and Gho YS (2009). Gram-positive bacteria produce membrane vesicles: proteomics-based characterization of Staphylococcus aureus-derived membrane vesicles. Proteomics 9(24): 5425-5436. doi: 10.1002/pmic.200900338

11. Hong SW, Kim MR, Lee EY, Kim JH, Kim YS, Jeon SG, and Kim YK (2011). Extracellular vesicles derived from Staphylococcus aureus induce atopic dermatitis-like skin inflammation. Allergy 66(3): 351359. doi: 10.1111/j.1398-9995.2010.02483.x

12. Kim MR, Hong SW, Choi EB, Lee WH, Kim YS, Jeon SG, Jang MH, Gho YS, and Kim YK (2012). Staphylococcus aureus-derived extracellular vesicles induce neutrophilic pulmonary inflammation via both Th1 and reproduction in any medium, provided the original author and source are acknowledged.

Please cite this article as: Swagata Bose, Shifu Aggarwal, Durg Vijai Singh and Narottam Acharya (2020). Extracellular vesicles: An emerging platform in gram-positive bacteria. Microbial Cell 7(12): 312-322. doi: $10.15698 /$ mic2020.12.737

and Th17 cell responses. Allergy 67(10): 1271-1281. doi 10.1111/all.12001

13. Rivera J, Cordero RJ, Nakouzi AS, Frases S, Nicola A, and Casadevall A (2010). Bacillus anthracis produces membrane-derived vesicles containing biologically active toxins. Proc Natl Acad Sci USA 107(44): 19002-19007. doi: 10.1073/pnas.1008843107

14. Kadurugamuwa JL and Beveridge TJ (1998). Delivery of the nonmembrane-permeative antibiotic gentamicin into mammalian cells by using Shigella flexneri membrane vesicles. Antimicrob Agents Chemother 42(6): 1476-1483. doi: 10.1128/aac.42.6.1476

15. Shockman GD and Barrett JF (1983). Structure, function, and assembly of cell walls of gram-positive bacteria. Ann Rev Microbiol 37(1): 501-527. doi: 10.1146/annurev.mi.37.100183.002441

16. Yu YJ, Wang XH, and Fan GC (2018). Versatile effects of bacteriumreleased membrane vesicles on mammalian cells and infectious/inflammatory diseases. Acta Pharmacol Sin 39(4): 514-533. doi: 10.1038/aps.2017.82

17. Schrempf H, Koebsch I, Walter S, Engelhardt H, and Meschke $H$ (2011). Extracellular Streptomyces vesicles: amphorae for survival and defence. Microb Biotechnol 4(2): 286-299. doi: 10.1111/j.1751 7915.2011.00251.x

18. Wang X, Thompson CD, Weidenmaier C, and Lee JC (2018). Release of Staphylococcus aureus extracellular vesicles and their application as a vaccine platform. Nat Commun 9(1): 1-13. doi: 10.1038/s41467-018-03847-z

19. Bielaszewska $M$, Rüter $C$, Bauwens $A$, Greune $L$, Jarosch $K A$, Steil $D$, Zhang W, He X, Lloubes R, Fruth A, Kim KS, Schmidt MA, Dobrindt U, Mellmann A, and Karch $H$ (2017). Host cell interactions of outer membrane vesicle-associated virulence factors of enterohemorrhagic Escherichia coli 0157: Intracellular delivery, trafficking and mechanisms of cell injury. PLoS Path 13(2): e1006159. doi 10.1371/journal.ppat.1006159

20. Lambert MA and Moss CW (1976). Cellular fatty acid composition of Streptococcus mutans and related streptococci. J Dental Res 55 (1suppl): 95-102. doi: 10.1177/002203457605500128011

21. Sado-Kamdem SL, Vannini L, and Guerzoni ME (2009). Effect of $\alpha$ linolenic, capric and lauric acid on the fatty acid biosynthesis in Staphylococcus aureus. Intl J Food Microbiol 129(3): 288-294. doi: 10.1016/j.ijfoodmicro.2008.12.010

22. Giesbrecht P, Kersten T, Maidhof H, and Wecke J (1998). Staphylococcal cell wall: morphogenesis and fatal variations in the presence of penicillin. Microbiol Mol Biol Rev 62(4): 1371-1414. doi: 10.1128/mmbr.62.4.1371-1414.1998

23. Demchick $P$ and Koch AL (1996). The permeability of the wall fabric of Escherichia coli and Bacillus subtilis. J Bacteriol 178: 768-773. doi: 10.1128/jb.178.3.768-773.1996

24. Toyofuku M, Cárcamo-Oyarce G, Yamamoto $T$, Eisenstein $F$, Hsiao CC, Kurosawa M, and Gademann K, Pilhofer M, Nomura N, and Eberl L (2017). Prophage-triggered membrane vesicle formation through 
peptidoglycan damage in Bacillus subtilis. Nat Commun 8(1): 1-10. doi: 10.1038/s41467-017-00492-w

25. Resch $U$, Tsatsaronis JA, Le Rhun A, Stubiger $G$, Rohde $M$, Kasvandik S, Holzmeister S, Tinnefeld P, Wai SN and Charpentier E (2016). A two-component regulatory system impacts extracellular membrane-derived vesicle production in Group A Streptococcus. mBio 7(6): e00207-16. doi:10.1128/mBio.00207-16

26. Schlag M, Biswas R, Krismer B, Kohler T, Zoll S, Yu W, Schwarz H, Peschel A, and Götz F (2010). Role of staphylococcal wall teichoic acid in targeting the major autolysin Atl. Mol Microbiol 75(4): 864-873. doi: $10.1111 / j .1365-2958.2009 .07007 . x$

27. Frankel MB and Schneewind O (2012). Determinants of murein hydrolase targeting to cross-wall of Staphylococcus aureus peptidoglycan. J Biol Chem 287(13): 10460-10471. doi: 10.1074/jbc.M111.336404

28. Alderwick $\sqcup$, Harrison J, Lloyd GS, and Birch HL (2015). The mycobacterial cell wall-peptidoglycan and arabinogalactan. CSH Perspect Med 5(8): a021113. doi: 10.1101/cshperspect.a021113

29. Aggarwal S, Jena S, Panda S, Sharma S, Dhawan B, Nath G, Singh NP, Nayak KC and Singh DV (2019). Antibiotic susceptibility, virulence pattern and typing of Staphylococcus aureus strains isolated from variety of infections in India. Front Microbiol 10: 2763. doi: 10.3389/fmicb.2019.02763

30. Lai CH, Listgarten MA, and Hammond BF (1981). Comparative ultrastructure of leukotoxic and non-leukotoxic strains of ActinobacilIus Actinomycetemcomitans. J Periodontal Res 16(4): 379-389. doi: 10.1111/j.1600-0765.1981.tb00989.x

31. Wai S N, Takade A, and Amako K (1995). The release of outer membrane vesicles from the strains of enterotoxigenicEscherichia coli. Microbiol Immunol 39(7): 451-456. doi: 10.1111/j.13480421.1995.tb02228.x

32. Honeywell-Nguyen PL and Bouwstra JA (2003). The in vitro transport of pergolide from surfactant-based elastic vesicles through human skin: a suggested mechanism of action. J Control Release 86(1): 145-156. doi: 10.1016/s0168-3659(02)00415-7

33. Sabra W, Lünsdorf $H$, and Zeng AP (2003). Alterations in the formation of lipopolysaccharide and membrane vesicles on the surface of Pseudomonas aeruginosa PAO1 under oxygen stress conditions. Microbiology 149(10): 2789-2795. doi: 10.1099/mic.0.26443-0

34. Brown L, Kessler A, Cabezas-Sanchez P, Luque-Garcia JL, and Casadevall A (2014). Extracellular vesicles produced by the Gram-positive bacterium Bacillus subtilis are disrupted by the lipopeptidesurfactin. Mol Microbiol 93(1): 183-198. doi: 10.1111/mmi.12650

35. Dubois JYF, Kouwen TR, Schurich AK, Reis CR, Ensing HT, Trip EN, Zweers JC, and van Dijl JM (2009). Immunity to the bacteriocinsublancin 168 is determined by the Sunl (YolF) protein of Bacillus subtilis. Antimicrob Agents Chemother 53(2): 651-661. doi: 10.1128/AAC.01189-08

36. Andreoni F, Toyofuku M, Menzi C, Kalawong R, Shambat SM, François $P$, Zinkernagel AS, and Eberl L (2019). Antibiotics stimulate formation of vesicles in Staphylococcus aureus in both phagedependent and-independent fashions and via different routes. Antimicrob Agents Chemother 63(2): e01439-18. doi: 10.1128/aac.0143918

37. Biagini M, Garibaldi M, Aprea S, Pezzicoli A, Doro F, Becherelli M, Taddei AR, Tani C, Tavarini S, Mora M, Teti G, D'Oro U, Nuti S, Soriani M, Margarit I, Rappuoli R, Grandi G, and Norais N (2015). The human pathogen Streptococcus pyogenes releases lipoproteins as lipoproteinrich membrane vesicles. Mol Cell Proteomics 14(8): 2138-2149. doi: 10.1074/mcp.M114.045880
38. Schreur PJW, Rebel JM, Smits MA, Van Putten JP, and Smith HE (2011). Lgt processing is an essential step in Streptococcus suis lipoprotein mediated innate immune activation. PloS one 6(7): e22299. doi: 10.1371/journal.pone.0022299

39. Lee JH, Choi CW, Lee T, Kim Sl, Lee JC, and Shin JH (2013). Transcription factor $\sigma B$ plays an important role in the production of extracellular membrane-derived vesicles in Listeria monocytogenes. Plos one 8(8): e73196. doi: 10.1371/journal.pone.0073196

40. Schorey J and Cheng Y (2018). Extracellular Vesicles promote host immunity during an $M$. tuberculosis infection through RNA Sensing. BioRxiv 346254. doi: 10.1101/346254

41. Cheng Y and Schorey JS (2019). Extracellular vesicles deliver Mycobacterium RNA to promote host immunity and bacterial killing. EMBO Rep 20(3): 346613. doi: 10.15252/embr.201846613

42. Kuehn MJ and Kesty NC (2005). Bacterial outer membrane vesicles and the host-pathogen interaction. Genes Dev 19(22): 2645-2655. doi: 10.1101/gad.1299905

43. Ellis TN and Kuehn MJ (2010). Virulence and immunomodulatory roles of bacterial outer membrane vesicles. Microbiol Mol Biol Rev 74(1): 81-94. doi: 10.1128/MMBR.00031-09

44. Wolf JM, Rivera J, and Casadevall A (2012). Serum albumin disrupts Cryptococcus neoformans and Bacillus anthracis extracellular vesicles. Cell Microbiol 14(5): 762-773. doi: 10.1111/j.14625822.2012.01757.x

45. Vecchiarelli A (2007). Fungal capsular polysaccharide and T-cell suppression: the hidden nature of poor immunogenicity. Crit Rev Immunol 27(6): 547-557. doi: 10.1615/critrevimmunol.v27.66.50

46. Smith H, Keppie J, and Stanley JL (1955). The chemical basis of the virulence of Bacillus anthracis. V. The specific toxin produced by $B$ anthracis in vivo. Brit J Exp Pathol 36(5): 460-472. PMID: 13269658

47. Jeon $\mathrm{H}$, Oh M H, Jun SH, Kim SI, Choi CW, Kwon HI, Na SH, Kim YJ, Nicholas A, Selasi GN, and Lee JC (2016). Variation among Staphylococcus aureus membrane vesicle proteomes affects cytotoxicity of host cells. Microb Path 93: 185-193. doi: 526 10.1016/j.micpath.2016.02.014

48. Surve MV, Anil A, Kamath KG, Bhutd $S$, Sthanam LK, Pradhan $A$, Srivastava R, Basu B, Dutta S, Sen S, and Modi D (2016). Membrane vesicles of group B Streptococcus disrupt feto-maternal barrier leading to preterm birth. PLoS Path 12(9): e1005816. doi: 10.1371/journal.ppat.1005816

49. Jeon J, Mok HJ, Choi Y, Park SC, Jo H, Her J, Han JK, Kim YK, Kim KP, and Ban C (2017). Proteomic analysis of extracellular vesicles derived from Propionibacterium acnes. Proteomics-Clin Appl 11(1-2): 1600040. doi: 10.1002/prca.201600040

50. Brown L, Wolf JM, Prados-Rosales R, and Casadevall A (2015). Through the wall: extracellular vesicles in Gram-positive bacteria, mycobacteria and fungi. Nat Rev Microbiol 13(10): 620-630. doi: 10.1038/nrmicro3480

51. Stelzner K, Hertlein T, Sroka A, Moldovan A, Paprotka K, Kessie D, Mehling H, Potempa J, Ohlesa K, Fraunholz MJ, and Rudel T (2020). Intracellular Staphylococcus aureus employs the cysteine protease staphopain A to induce host cell death in epithelial cells. bioRxiv. doi: 10.1101/2020.02.10.936575

52. Otto M (2010). Basis of virulence in community-associated methicillin-resistant Staphylococcus aureus. Ann Rev Microbiol 64: 143-162. doi: 10.1146/annurev.micro.112408.134309

53. Schlievert PM, Strandberg KL, Lin YC, Peterson ML, and Leung DY (2010). Secreted virulence factor comparison between methicillinresistant and methicillin-sensitive Staphylococcus aureus, and its rele- 
vance to atopic dermatitis. J Allergy Clin Immunol 125(1): 39-49. doi: 10.1016/j.jaci.2009.10.039

54. Hong SW, Choi EB, Min TK, Kim JH, Kim MH, Jeon SG, Lee BJ, Gho YS, Jee YK, Pyun BY, and Kim YK (2014). An important role of $\alpha$ hemolysin in extracellular vesicles on the development of atopic dermatitis induced by Staphylococcus aureus. PLoS One 9(7): e100499. doi: 10.1371/journal.pone.0100499

55. Portnoy DA, Jacks PS, and Hinrichs DJ (1988). Role of hemolysin for the intracellular growth of Listeria monocytogenes. J Exp Med 167(4): 1459-1471. doi: 10.1084/jem.167.4.1459

56. Cossart P, Vicente MF, Mengaud J, Baquero F, Perez-Diaz JC, and Berche $P$ (1989). Listeriolysin $O$ is essential for virulence of Listeria monocytogenes: direct evidence obtained by gene complementation. Infect Immun 57(11): 3629-3636. doi: 10.1128/iai.57.11.36293636.1989

57. Olaya-Abril A, Prados-Rosales R, McConnell MJ, Martín-Peña R, González-Reyes JA, Jiménez-Munguía I, and Estévez H (2014). Characterization of protective extracellular membrane-derived vesicles produced by Streptococcus pneumoniae. J Proteomics 106: 46-60. doi: 10.1016/j.jprot.2014.04.023

58. Hirst RA, Gosai B, Rutman A, Guerin CJ, Nicotera P, Andrew PW, and O'Callaghan C (2008). Streptococcus pneumoniae deficient in pneumolysin or autolysin has reduced virulence in meningitis. J Infect Dis 197(5): 744-751. doi: 10.1086/527322

59. Echeverria-Valencia G, Flores-Villalva S, and Espitia Cl (2018). Virulence factors and pathogenicity of Mycobacterium. MycobacteriumResearch and Development. Wellman Ribón, Intech Open 231-255. doi: 10.5772/intechopen.72027

60. Marsollier L, Brodin $\mathrm{P}$, Jackson $\mathrm{M}$, Korduláková J, Tafelmeyer $\mathrm{P}$, Carbonnelle E, Jacques A, Milon G, Legras P, Andre JPS, Leroy C, Cottin J, Guillou MLJ, Reysset G, and Cole ST (2007). Impact of Mycobacterium ulcerans biofilm on transmissibility to ecological niches and $\mathrm{Bu}$ ruli ulcer pathogenesis. PLoS Path 3(5): e62. doi: 10.1371/journal.ppat.0030062

61. De Voss JJ, Rutter K, Schroeder BG, Su H, Zhu Y, and Barry CE (2000). The salicylate-derived mycobactin siderophores of Mycobacterium tuberculosis are essential for growth in macrophages. Proc Natl Acad Sci USA 97(3): 1252-1257. doi: 10.1073/pnas.97.3.1252

62. Reddy PV, Puri RV, Chauhan P, Kar R, Rohilla A, Khera A, and Tyagi AK (2013). Disruption of mycobactin biosynthesis leads to attenuation of Mycobacterium tuberculosis for growth and virulence. J Infect Dis 208(8): 1255-1265. doi: 10.1093/infdis/jit250

63. Gurung M, Moon DC, Choi CW, Lee JH, Bae YC, Kim J, Lee YC, Seol SY, Cho DT, Kim SII, and Lee JC (2011). Staphylococcus aureus produces membrane-derived vesicles that induce host cell death. PloS one 6(11): e27958. doi: 10.1371/journal.pone.0027958

64. Cheung GY, Joo HS, Chatterjee SS, and Otto M (2014). Phenolsoluble modulins-critical determinants of staphylococcal virulence. FEMS Microbiol Rev 38(4): 698-719. doi: 10.1111/1574-6976.12057

65. Wang X, Eagen WJ, and Lee JC (2020). Orchestration of human macrophage NLRP3 inflammasome activation by Staphylococcus aureus extracellular vesicles. Proc Natl Acad Sci USA 117(6): 3174-3184. doi: 10.1073/pnas.1915829117

66. Davis JM and Ramakrishnan L (2009). The role of the granuloma in expansion and dissemination of early tuberculous infection. Cell 136(1): 37-49. doi: 10.1016/j.cell.2008.11.014

67. Prados-Rosales R, Baena A, Martinez LR, Luque-Garcia J, Kalscheuer R, Veeraraghavan U, Camara C, Nosanchuk JD, Besra GS, Chen B, Jimenez J, Glatman-Freedman A, Jr. Jacobs WR, Porcelli SA, and Casadevall $A$, (2011). Mycobacteria release active membrane vesicles that modulate immune responses in a TLR2-dependent manner in mice. J Clin Invest 121(4): 1471-1483. doi: 10.1172/JCI44261

68. Beatty WL, Rhoades ER, Ullrich HJ, Chatterjee D, Heuser JE, and Russell DG (2000). Trafficking and release of mycobacterial lipids from infected macrophages. Traffic 1(3): 235-247. doi: 10.1034/j.16000854.2000.010306.x

69. Athman JJ, Sande OJ, Groft SG, Reba SM, Nagy N, Wearsch PA Richardson ET, Rojas R, Boom WH, Shukla S, and Harding CV (2017) Mycobacterium tuberculosis membrane vesicles inhibit $\mathrm{T}$ cell activation. J Immunol 198(5): 2028-2037. doi: 10.4049/jimmunol.1601199

70. Domingues S and Nielsen KM (2017). Membrane vesicles and horizontal gene transfer in prokaryotes. Curr Opin Microbiol 38: 1621. doi: 10.1016/j.mib.2017.03.012

71. Erdmann S, Tschitschko B, Zhong L, Raftery MJ, and Cavicchioli R (2017). A plasmid from an Antarctic haloarchaeon uses specialized membrane vesicles to disseminate and infect plasmid-free cells. Nat Microbiol 2(10): 1446-1455. doi: 10.1038/s41564-017-0009-2

72. Tran F and Boedicker JQ (2017). Genetic cargo and bacterial species set the rate of vesicle-mediated horizontal gene transfer. Sci Rep 7(1): 1-10. doi: 10.1038/s41598-017-07447-7

73. Klieve AV, Yokoyama MT, Forster RJ, Ouwerkerk D, Bain PA, and Mawhinney EL (2005). Naturally occurring DNA transfer system associated with membrane vesicles in cellulolytic Ruminococcus spp. of ruminal origin. Appl Environ Microbiol 71(8): 4248-4253. doi: 10.1128/AEM.71.8.4248-4253.2005

74. Lindsay JA (2014a). Evolution of Staphylococcus aureusand MRSA during outbreaks. Infect Gen Evol 21: 548-553. doi: 10.1016/j.meegid.2013.04.017

75. Lindsay JA (2014b). Staphylococcus aureus genomics and the impact of horizontal gene transfer. Intl J Med Microbiol 304(2): 103-109. doi: 10.1016/j.ijmm.2013.11.010

76. Sharma A and Satyanarayana T (2013). Comparative genomics of Bacillus species and its relevance in industrial microbiology. Genomics Insights 6: 25-36. doi: 10.4137/GEI.S12732

77. Tzipilevich E, Habusha M, and Ben-Yehuda S (2017). Acquisition of phage sensitivity by bacteria through exchange of phage receptors. Cell 168(1-2): 186-199. doi: 10.1016/j.cell.2016.12.003

78. Gray TA and Derbyshire KM (2018). Blending genomes: distributive conjugal transfer in mycobacteria, a sexier form of HGT. Mol Microbiol 108(6): 601-613. doi: 10.1111/mmi.13971

79. Choi SJ, Kim MH, Jeon J, Kim OY, Choi Y, Seo J, Hong SW, Lee WH, Jeon SG, Gho YS, Jee YK, and Kim YK (2015). Active immunization with extracellular vesicles derived from Staphylococcus aureus effectively protects against staphylococcal lung infections, mainly via Th1 cellmediated immunity. PloS One 10(9):e136021. doi 10.1371/journal.pone.0136021

80. Baxter D (2007) Active and passive immunity, vaccine types, excipients and licensing. Occup Med 57(8): 552-556. doi: 10.1093/occmed/kqm110

81. Sugimoto $\mathrm{S}$, Okuda $\mathrm{KI}$, Miyakawa $\mathrm{R}$, Sato $\mathrm{M}$, Arita-Morioka $\mathrm{KI}$, Chiba A, Yamanaka K, Ogura T, Mizunoe Y, and Sato C (2016). Imaging of bacterial multicellular behaviour in biofilms in liquid by atmospheric scanning electron microscopy. Sci Rep 6(1): 1-13. doi: $10.1038 /$ srep25889

82. Corthésy B, Gaskins HR, and Mercenier A (2007). Cross-talk between probiotic bacteria and the host immune system. J Nutr 137(3): 781S-790S. doi: 10.1093/jn/137.3.781S

83. Muralinath M, Kuehn MJ, Roland KL, and Curtiss R (2011). Immunization with Salmonella enterica serovar Typhimurium-derived outer membrane vesicles delivering the pneumococcal protein PspA confers 
protection against challenge with Streptococcus pneumoniae. Infect Immun 79(2): 887-894. doi: 10.1128/IAI.00950-10

84. Gehring AJ, Dobos KM, Belisle JT, Harding CV, and Boom WH (2004). Mycobacterium tuberculosis LprG (Rv1411c): a novel TLR-2 ligand that inhibits human macrophage class II MHC antigen processing. J Immunol 173(4): 2660-2668. doi: 10.4049/jimmunol.173.4.2660

85. Beveridge TJ and Kadurugamuwa JL (1996). Periplasm, periplasmic spaces, and their relation to bacterial wall structure: novel secretion of selected periplasmic proteins from Pseudomonas aeruginosa. Microb Drug Res 2(1): 1-8. doi: 10.1089/mdr.1996.2.1

86. Schooling SR, Hubley A, and Beveridge TJ (2009). Interactions of DNA with biofilm-derived membrane vesicles. J Bacteriol 191(13): 4097-4102. doi: 10.1128/JB.00717-08

87. Mashburn-Warren LM and Whiteley M (2006). Special delivery: vesicle trafficking in prokaryotes. Mol Microbiol 61(4): 839-846. doi: 10.1111/j.1365-2958.2006.05272.x

88. Yáñez-Mó M, Siljander PR-M, Andreu Z, Zavec AB, Borràs FE, Buzas EI, Buzas K, Casal E, Cappello F, Carvalho J, Colás E, Cordeiro-da Silva A, Fais S, Falcon- Perez JM, Ghobrial IM, Giebel B, Gimona M, Graner M, Gursel I, Gursel M, Heegaard NHH, Hendrix A, Kierulf P, Kokubun K, Kosanovic M, Kralj-Iglic V, Krämer-Albers EM, Laitinen S, Lässer C, Lener T, et al (2015). Biological properties of extracellular vesicles and their physiological functions. J Extracell Vesicles 4(1): 27066. doi: 10.3402/jev.v4.27066

89. Liao S, Klein MI, Heim KP, Fan Y, Bitoun JP, Ahn SJ, Burne RA, Koo $\mathrm{H}$, Brady LJ, and Wen ZT (2014). Streptococcus mutans extracellular
DNA is upregulated during growth in biofilms, actively released via membrane vesicles, and influenced by components of the protein secretion machinery. J Bacteriol 196(13): 2355-2366. doi: 10.1128/JB.01493-14

90. Panda S and Singh DV (2018). Biofilm formation by ica-negative ocular isolates of Staphylococcus haemolyticus. Front Microbiol 9: 2687. doi: 10.3389/fmicb.2018.02687

91. Uddin MJ, Dawan J, Jeon G, Yu T, He X, and Ahn J (2020). The role of bacterial membrane vesicles in the dissemination of antibiotic resistance and as promising carriers for therapeutic agent delivery. Microorganisms 8(5):670.doi: 10.3390/microorganisms 8050670

92. Chabelskaya S, Gaillot O, and Felden B (2010). A Staphylococcus aureus small RNA is required for bacterial virulence and regulates the expression of an immune-evasion molecule. PLoS Pathog 6(6): e1000927. doi: 10.1371/journal.ppat.1000927

93. Im H, Lee S, Soper SA, Mitchell RJ (2017). Staphylococcus aureus extracellular vesicles (EVs): surface-binding antagonists of biofilm formation. Mol BioSyst 13(12):2704-14. doi: 10.1039/c7mb00365j

94. Acevedo R, Fernandez S, Zayas C, Acosta A, Sarmiento ME, Ferro VA, Rosenqvist E, Campa C, Cardoso D, Garcia C, and Perez JL (2014). Bacterial outer membrane vesicles and vaccine applications. Front Immunol 5:121. doi: 10.3389/fimmu.2014.00121

95. Gupta S and Rodriguez GM (2018). Mycobacterial extracellular vesicles and host pathogen interactions. Path Dis 76(4): fty031. doi: 10.1093/femspd/fty031 